\title{
Treatment of localized neuropathic pain of different etiologies with the $5 \%$ lidocaine medicated plaster - a case series
}

This article was published in the following Dove Press journal:

International Journal of General Medicine

19 December 2014

Number of times this article has been viewed

\author{
Rudolf Likar' \\ Susanne Demschar' \\ Ingo Kager' \\ Stefan Neuwersch' \\ Wolfgang Pipam' \\ Reinhard Sittl ${ }^{2}$ \\ 'Department of Anesthesiology and \\ Intensive Care, Hospital Klagenfurt, \\ Klagenfurt, Austria; ${ }^{2}$ Department of \\ Anesthesiology, Interdisciplinary Pain \\ Centre, University Hospital Erlangen, \\ Erlangen, Germany
}

Objective: To assess the efficacy and safety of the topical 5\% lidocaine medicated plaster in the treatment of localized neuropathic pain.

Study design: This was a case series at an Austrian pain clinic, using retrospective analysis. Patients and methods: Data of 27 patients treated for localized neuropathic pain with the $5 \%$ lidocaine medicated plaster were retrospectively analyzed. Assessment included changes in overall pain intensity, in intensity of different pain qualities, and of hyperalgesia and allodynia, and changes in sleep quality.

Results: Patients (17 female, ten male; mean age 53.4 \pm 11.4 years) presented mainly with dorsalgia (16 patients) or postoperative/posttraumatic pain (seven patients); one patient suffered from both. The mean overall pain intensity prior to treatment with lidocaine medicated plaster was $8.4 \pm 1.2$ on the 11-point Likert scale. In the majority of cases, the lidocaine plaster was applied concomitantly with preexisting pain medication ( $81.5 \%$ of the patients). During the 6-month observation period, overall mean pain intensity was reduced by almost 5 points (4.98) to 3.5 \pm 2.6 . Substantial reductions were also observed for neuralgiform pain (5 points from $7.9 \pm 2.6$ at baseline) and burning pain (3 points from 5.2 \pm 4.1 ). Sleep quality improved from $4.6 \pm 2.6$ at baseline to $5.5 \pm 1.8$. Stratification by pain diagnosis showed marked improvements in overall pain intensity for patients with dorsalgia or postoperative/posttraumatic pain. The lidocaine plaster was well tolerated.

Conclusion: Overall, topical treatment with the $5 \%$ lidocaine medicated plaster was associated with effective pain relief and was well tolerated.

Keywords: localized neuropathic pain, dorsalgia, postoperative/posttraumatic pain, topical analgesic, 5\% lidocaine medicated plaster

\section{Introduction}

Neuropathic pain is common; prevalence rates do, however, show considerable variations with different methods of estimation used, and range from $3.3 \%$ to $17.9 \%$ of the population in industrial countries. ${ }^{1}$ It is defined as pain arising as a direct consequence of a lesion or disease affecting the somatosensory system, ${ }^{2}$ and may be of either central or peripheral origin depending on the site of the lesion within the nervous system. ${ }^{3}$ The condition is debilitating, with a serious negative impact on patient functioning and quality of life, ${ }^{1,4-6}$ and is often reported with higher interference of pain in daily activities and overall higher disease burden compared to nonneuropathic pain. ${ }^{5,7}$ Although cause, severity, and characteristics of the pain may vary, neuropathic pain of different underlying conditions tends to share common abnormal sensory perceptions that are generally distinguished as positive or negative signs and symptoms (eg, loss of noxious,
Correspondence: Rudolf Likar Abteilung für Anästhesiologie und Intensivmedizin, Klinikum Klagenfurt, Feschnigstrasse II, 9026 Klagenfurt, Austria

Tel +4346353834303

Fax +4346353834309

Email rudolf.likar@kabeg.at 
mechanical, or thermal perception and/or positive signs, such as paresthesias, allodynia, and hyperalgesia). These may occur alone or - more frequently - in combination. ${ }^{9,10}$ Also in common are typical pain descriptors, such as burning or shooting pain with unusual tingling, crawling, or electrical sensations. ${ }^{9}$

Because of its complex etiology, neuropathic pain can be difficult to treat, and the rate of nonresponders to pharmacological treatment can be relatively high. ${ }^{10}$ Pharmacotherapy of neuropathic pain differs from the treatment of nonneuropathic pain. Guidelines recommend the use of antidepressants and anticonvulsants or topical treatment for the management of neuropathic pain, with opioids usually recommended as second- or third-line therapies. ${ }^{11-14}$ Paracetamol and nonsteroidal anti-inflammatory drugs are largely ineffective in neuropathic pain. ${ }^{15}$ Systemic treatments may be associated with - frequently dose-dependent - tolerability issues and/or drug interactions. ${ }^{16}$ Topical medications may lead to adverse skin reactions in some patients; ${ }^{17}$ they are, however, generally well tolerated, and thus constitute a valuable option for localized neuropathic pain treatment.

This case series documents the use of the topical analgesic 5\% lidocaine medicated plaster for the relief of pain symptoms in patients with localized neuropathic pain of different etiologies. The 5\% lidocaine medicated plaster is recommended as first-line treatment for localized peripheral neuropathic pain. ${ }^{12,14}$ It is indicated in approximately 50 countries worldwide for the treatment of neuropathic pain associated with previous herpes zoster infection (postherpetic neuralgia), and additionally in nine of these countries for the treatment of localized neuropathic pain. Efficacy and safety of the plaster in the treatment of neuropathic pain was demonstrated in a number of randomized clinical studies and open, long-term observations; for detailed information, we refer the reader to a recent comprehensive review. ${ }^{18}$ Owing to its negligible risk for drug-drug interactions and systemic side effects, ${ }^{18}$ the lidocaine plaster is also a suitable treatment option for elderly, often polymedicated patients.

\section{Patients and methods}

This retrospective analysis included patients who received treatment with the 5\% lidocaine medicated plaster for localized neuropathic pain symptoms at the Center for Interdisciplinary Pain Therapy and Palliative Medicine in Klagenfurt, Austria. Data had been collected by the treating clinicians at monthly intervals using standardized forms. Documentation included demographic characteristics, pain diagnosis, overall pain intensity, presence/absence of hyperalgesia, allodynia, paresthesia, abnormal temperature sensations, and burning, tingling, or neuralgiform pain, number of daily applied lidocaine plasters, prior and concomitant medications, sleep quality, and the occurrence of adverse events. All pain parameters as well as sleep quality were rated on an 11-point Likert scale $(0=$ not present to $10=$ worst-possible state, eg, worst pain imaginable for the parameter pain intensity). For the parameter sleep, 0 represented worst-possible sleep and 10 best-possible sleep.

Data over a 6-month observation period were retrieved from the center's database and analyzed by one of the authors (SD) with the approval of the center's ethics committee. All data were analyzed descriptively, and missing data were not imputed.

\section{Results}

This analysis included 27 patients ( 17 female, ten male) aged between 38 and 91 years (mean age 53.4 \pm 11.4 years). Sixteen patients were diagnosed with cervical, thoracic, and/or lumbar spine syndrome; neck, thoracic spine, and lower back pain are all coded under the term "dorsalgia" (M54) in the International Statistical Classification of Diseases and Related Health Problems, 10th revision diagnosis codes. ${ }^{19}$ This diagnostic code is used throughout the paper. Seven patients presented with postoperative/posttraumatic pain. One patient suffered from neuropathic pain in the cervical region and following hip surgery, and is listed under both groups (Table 1). Patients had experienced pain for a mean of 5.4 \pm 5.7 years (median 3 years), and presented with a mean pain intensity of $8.4 \pm 1.2$ (11-point Likert scale). Individual baseline pain scores are listed in Table 1 . The majority suffered from neuralgiform pain $(92.6 \%)$ and from burning pain $(63.0 \%)$; six patients $(22.2 \%)$ had allodynia, and eight (29.6\%) experienced hyperalgesia.

\section{Lidocaine plaster treatment and concomitant analgesics}

With the exception of one patient who received one to two plasters/week, all others applied the 5\% lidocaine medicated plaster daily for a 12 -hour period. The majority (85.2\%) used one plaster/day, one applied half a plaster, two administered two plasters/day to the painful area, and one patient's requirements varied between 0.5 and one daily plaster. The plasters were mainly applied concomitantly with preexisting pain medication (81.5\% of the patients); one patient received the plaster as monotherapy, and four patients used other analgesics if needed. Concomitant pain medications included nonsteroidal anti-inflammatory 
Table I Pain diagnoses and pain location. Two patients discontinued after 4, and one patient after 5 treatment months

\begin{tabular}{|c|c|c|c|c|}
\hline \multirow[t]{2}{*}{ Pain diagnosis } & \multirow[t]{2}{*}{$\mathbf{n}$} & \multirow[t]{2}{*}{ Pain location } & \multicolumn{2}{|c|}{ Overall pain intensity (NRS $0-10$ ) } \\
\hline & & & Baseline & $\begin{array}{l}\text { After } 6 \text { months } \\
\text { treatment }\end{array}$ \\
\hline \multirow[t]{17}{*}{ Dorsalgia } & \multirow[t]{17}{*}{17} & \multirow[t]{6}{*}{ Lumbar region } & 8 & 4 \\
\hline & & & 7 & 5.5 \\
\hline & & & 9 & 4 \\
\hline & & & 10 & 3 \\
\hline & & & 8.5 & 2 \\
\hline & & & 8 & 4 (after 4 months) \\
\hline & & Left popliteal fossa & 10 & 4 \\
\hline & & Left hip and leg & 6 & I \\
\hline & & Left lower leg & 10 & 4 \\
\hline & & \multirow[t]{3}{*}{ Lumbar and cervical region } & 7.5 & 9 \\
\hline & & & 6.5 & I \\
\hline & & & 8 & 4 \\
\hline & & Lumbar and thoracic region & 8.5 & 8 \\
\hline & & Lumbar region and forehead & 10 & 7 \\
\hline & & Cervical, thoracic, lumbar region & 7 & 0 \\
\hline & & Cervical region ${ }^{\mathrm{a}}$ & 9 & 2.5 (after 5 months) \\
\hline & & Cervical and thoracic region & 8 & 6 \\
\hline Postoperative/posttraumatic & \multirow[t]{8}{*}{8} & Left mandible & 7 & 1.5 \\
\hline \multirow[t]{7}{*}{ pain } & & Left hip ${ }^{a}$ & 9 & 2.5 (after 5 months) \\
\hline & & Right ankle & 8.5 & 1 \\
\hline & & Left hand & 9 & 3 \\
\hline & & Right wrist & 9.5 & 0 \\
\hline & & Left groin & 10 & 5 \\
\hline & & Thoracic & 7 & 3 \\
\hline & & & 9 & 0 \\
\hline Phantom limb pain & 1 & Stump left leg & 10 & I \\
\hline Postherpetic neuralgia & I & Thoracic, left side & 9 & 6 \\
\hline Not specified & I & Left wrist & 8 & 3.5 (after 4 months) \\
\hline
\end{tabular}

Note: ${ }^{\text {TTh }}$ Thatient experienced neuropathic pain in the cervical region and following hip surgery.

Abbreviation: NRS, numerical rating scale.

drugs (diclofenac, ketoprofen, mefenamic acid, naproxen, dexibuprofen, indomethacin, celecoxib), opioids (tramadol, transdermal buprenorphine, hydromorphone), other analgesics (paracetamol, metamizole, dihydroergotamine mesylate, triptans), gabapentinoids (gabapentin, pregabalin), drugs with antidepressive properties (amitriptyline, duloxetine, citalopram, escitalopram, olanzapine, trazodone hydrochloride), benzodiazepines (tetrazepam, oxazepam, clonazepam), muscle relaxants (baclofen, tizanidine), methylprednisolone, esketamine hydrochloride, mexiletine hydrochloride, and orphenadrine. Two patients discontinued treatment after 4 months, and another after 5 months of observation.

\section{Efficacy}

All except one patient $(96.3 \%)$ reported a reduction in pain under lidocaine plaster treatment (Table 1); pain relief was $\geq 5$ points on the Likert scale for 16 patients $(59.3 \%)$. Mean overall pain intensity improved substantially over the first treatment month, and remained at this level during the entire observation period (Figure 1). At the end of 6 months, mean pain intensity had been reduced by 5 points to $3.5 \pm 2.6$.
Substantial reductions were also observed for the two most prominent pain qualities - neuralgiform pain and burning pain - with $2.9 \pm 2.6$ (reduction by 5 points) and $2.2 \pm 2.7$ (reduction by 3 points), respectively, at the end of observation (Figure 1). All other assessed pain parameters were only

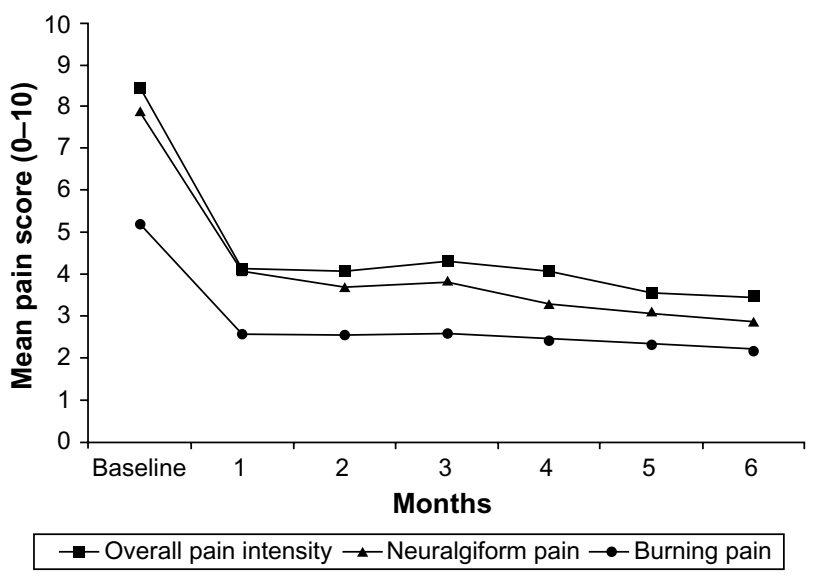

Figure I Reduction in mean overall pain intensity, neuralgiform pain, and burning pain following treatment with the $5 \%$ lidocaine medicated plaster $(n=27$ baseline to 4 months, $\mathrm{n}=25$ at 5 months, $\mathrm{n}=24$ at 6 months). 
experienced by a few patients. Except for tingling sensations (three patients, baseline 1.2 $\pm 2.8,6$ months $1.2 \pm 2.5$ ), all mean scores decreased during the observation period: allodynia (six patients) from $2.0 \pm 3.9$ to $1.0 \pm 2.3$, hyperalgesia (eight patients) from $2.5 \pm 4.0$ to $1.3 \pm 2.5$, paresthesias (nine patients) from $2.1 \pm 3.5$ to $0.7 \pm 2.1$, and abnormal temperature sensation (five patients) from $1.6 \pm 3.1$ to $1.0 \pm 2.3$. Mean sleep quality also improved from $4.6 \pm 2.6$ at baseline to $5.5 \pm 1.8$ after 6 treatment months.

\section{Stratification by pain diagnosis}

Most patients were diagnosed with either dorsalgia (16 patients) or postoperative/posttraumatic pain (seven patients). One patient suffered from neuropathic pain in the cervical region and following hip surgery, and was included in both subgroups.

\section{Dorsalgia}

In this subgroup, mean overall pain intensity for 15 patients with data for the entire 6-month observation improved by 4.1 points (baseline $8.3 \pm 1.3$, end of observation $4.2 \pm 2.6$ ). The majority of patients presented with neuralgiform pain (94.1\%) and/or burning pain (58.8\%). Treatment with the lidocaine plaster reduced mean neuralgiform pain by 4.4 points from $8.1 \pm 1.4$ at baseline to $3.7 \pm 2.8$ after 6 months and mean burning pain by 3.7 points from $8.1 \pm 1.4$ to $4.4 \pm 2.5$. The two patients discontinuing after 4 and 5 months of observation reported improvements of 4 and 6.5 points, respectively, in overall pain intensity, and 4 and 6 points, respectively, in neuralgiform pain; one patient also suffered from burning pain, which was reduced by 4 points.

Two patients experienced allodynia and hyperalgesia at baseline, which were completely relieved in one patient from a score of 10 after 3 months of lidocaine plaster treatment, but remained on a score of 9 during the 6-month observation for the second patient. Hyperalgesia was present at baseline in another two patients, one of whom also experienced allodynia after 2 treatment months (score of 6, which was reduced to 4 after 6 months). Hyperalgesia was partly relieved in these patients. One patient experienced hyperalgesia after 4 months of treatment.

\section{Postoperative/posttraumatic pain}

Mean overall pain intensity was reduced by 6.7 points after the 6-month observation for the seven patients with data for the entire 6-month observation period (from baseline 8.6 \pm 1.2 to $1.9 \pm 1.8)$. Seven of the eight patients $(87.5 \%)$ with postoperative/posttraumatic pain suffered from neuralgiform pain, and five $(62.5 \%)$ from burning pain. One patient experienced neuralgiform pain after 3 months of treatment ( 6.5 points), which was reduced to 3 points at the end of observation. One patient discontinued after 5 months; overall pain intensity and neuralgiform pain improved by 6.5 and 6 points, respectively. Mean intensity of neuralgiform pain decreased by 6.6 points from $8.9 \pm 1.1$ to $2.3 \pm 1.8$ for the other six patients in this subgroup. Mean burning pain decreased by 6.3 points from $8.6 \pm 0.9$ to $2.3 \pm 2.5$. One patient experienced hyperalgesia, which was completely relieved after 3 months, and one had both hyperalgesia and allodynia (pain was reduced by 6 points after 6 months).

\section{Safety}

Fourteen adverse events were reported during the observation: eight occurred in the first month, four in the second, and two in the third month. They included fatigue (four cases), dizziness (two cases), lack of concentration (two cases), stomach pain (two cases), constipation, nausea, dry mouth, and hair loss. Two cases of fatigue were considered severe. None of the adverse events was considered related to lidocaine plaster treatment.

\section{Discussion}

Administration of the 5\% lidocaine medicated plaster provided marked pain relief in this patient cohort suffering from localized neuropathic dorsalgia or postoperative/posttraumatic pain. The treatment was generally well tolerated over the 6-month observation period. The good efficacy and tolerability in long-term treatment is supported by clinical studies, demonstrating that the $5 \%$ lidocaine medicated plaster has high potential for long-term use. ${ }^{20-22}$ Systemic exposure is very low, with maximum plasma levels far below clinically relevant systemic levels, ${ }^{23}$ which suggests a minimal risk of systemic adverse events and pharmacokinetic interactions with concomitant medications.

Back pain is the most common diagnosis for chronic pain patients; ${ }^{24}$ the presence of a neuropathic component increases the economic burden of back or neck pain. ${ }^{25}$ To our knowledge, this is only the second case series showing improvement of neuropathic pain in various spinal regions using the lidocaine plaster since the definition of low-back pain as a mixed-pain syndrome, ${ }^{26}$ and thus a greater awareness of the treating physicians for the need to distinguish between nociceptive and neuropathic pain components. In our analysis, patients affected by dorsalgia in various spinal regions (cervical, thoracic, lumbar) all suffered from neuropathic pain. We did not include patients treated with the 
lidocaine plaster for neuropathic pain after disk herniation; these patients were analyzed separately. ${ }^{27}$ Over the observation period, administration of the lidocaine plaster markedly improved pain intensity in our patient group; this confirms the positive findings from a series of case reports submitted for a pain-specialist meeting: ${ }^{28}$ good efficacy of the lidocaine plaster was suggested for $76 \%$ of the patients with localized chronic low-back pain with a neuropathic component.

Postoperative/posttraumatic pain was diagnosed for a quarter of the patients $(25.9 \%)$. The disease burden for patients with postoperative/posttraumatic neuropathic pain is high, with poor functioning and sleep, depression, and poor quality of life; the economic burden is also substantial. ${ }^{29}$ The lidocaine plaster proved effective over the 6-month treatment period in our small patient cohort: pain intensity substantially decreased. Our findings are well in agreement with previous studies and case series investigating treatment of postoperative/posttraumatic pain with the lidocaine plaster. ${ }^{18}$ Three-month adjunctive plaster treatment provided significant relief of chronic neuropathic pain following surgical and nonsurgical trauma; $47.5 \%$ of the patients experienced $\geq 50 \%$ reduction of pain. ${ }^{30} \mathrm{~A}$ prospective case series of patients with painful scars including nine patients with orthopedic surgery showed the effectiveness of the lidocaine plaster treatment over a mean treatment period of 3.5 months. ${ }^{31}$ This study demonstrated for the first time a decrease in the painful surface area. Good efficacy of the lidocaine plaster as add-on treatment was also demonstrated by case reports of patients with neuropathic pain following surgical and nonsurgical trauma collected for a meeting of pain specialists. ${ }^{28}$ Seventy-six percent of the patients were considered as much or very much improved.

The lidocaine plaster was well tolerated. It is of interest that application-site reactions, which are the most common adverse events reported for this topical treatment, ${ }^{18}$ did not occur. All documented adverse events were considered not related to the lidocaine plaster, and probably occurred because of concomitant analgesic medications.

\section{Conclusion}

The 5\% lidocaine medicated plaster was effective and well tolerated in a patient group mainly including patients with dorsalgia or postoperative/posttraumatic neuropathic pain. Although this is only a case series, it nevertheless supports the existing literature and experience with the lidocaine plaster for various localized neuropathic pain syndromes. The observed benefits suggest a topical therapy, such as the $5 \%$ lidocaine medicated plaster, as a useful medication and simple solution, in particular owing to the proven efficacy in combination with very low systemic lidocaine absorption and thus low risk of systemic adverse events and of drug-drug interactions with concomitant medications.

\section{Acknowledgments}

The authors did not receive funding for this analysis. Writing and editorial assistance was provided by Birgit Brett and Elke Grosselindemann (Brett Medical Writing). All costs associated with the publication of the manuscript were met by Grünenthal $\mathrm{GmbH}$, Aachen, Germany.

\section{Disclosure}

RL has received honoraria for lectures and for serving on advisory boards for Grünenthal. RS has received lecture fees from Grünenthal GmbH. The other authors report no conflicts of interest in this work.

\section{References}

1. Smith BH, Torrance N. Epidemiology of neuropathic pain and its impact on quality of life. Curr Pain Headache Rep. 2012;16:191-198.

2. Treede RD, Jensen TS, Campbell JN, et al. Neuropathic pain: redefinition and a grading system for clinical and research purposes. Neurology. 2008;70:1630-1635.

3. Sadosky A, McDermott AM, Brandenburg NA, Strauss M. A review of the epidemiology of painful diabetic peripheral neuropathy, postherpetic neuralgia, and less commonly studied neuropathic pain conditions. Pain Pract. 2008;8:45-56.

4. Jensen MP, Chodroff MJ, Dworkin RH. The impact of neuropathic pain on health-related quality of life: review and implications. Neurology. 2007;68:1178-1182.

5. Attal N, Lanteri-Minet M, Laurent B, Fermanian J, Bouhassira D. The specific disease burden of neuropathic pain: results of a French nationwide survey. Pain. 2011;152:2836-2843.

6. O'Connor AB. Neuropathic pain. Quality-of-life impact, costs and cost effectiveness of therapy. Pharmacoeconomics. 2009;27:95-112.

7. Ohayon M, Stingl JC. Prevalence and comorbidity of chronic pain in the German general population. J Psychiatr Res. 2012;46:444-450.

8. Smith BH, Torrance N, Bennett MI, Lee AJ. Health and quality of life associated with chronic pain of predominantly neuropathic origin in the community. Clin J Pain. 2007;23:143-149.

9. Baron R, Binder A, Wasner G. Neuropathic pain: diagnosis, pathophysiological mechanisms, and treatment. Lancet Neurol. 2010;9: 807-819.

10. Hansson PT, Attal N, Baron R, Cruccu G. Toward a definition of pharmacoresistant neuropathic pain. Eur J Pain. 2009;13:439-440.

11. Finnerup NB, Otto M, Jensen TS, Sindrup SH. An evidence-based algorithm for the treatment of neuropathic pain. MedGenMed. 2007;9:36.

12. Dworkin RH, O'Connor AB, Audette J, et al. Recommendations for the pharmacological management of neuropathic pain: an overview and literature update. Mayo Clin Proc. 2010;85(Suppl.):S3-S14.

13. Moulin DE, Clark AJ, Gilron I, et al. Pharmacological management of chronic neuropathic pain: consensus statement and guidelines from the Canadian Pain Society. Pain Res Manag. 2007;12:13-21.

14. Attal N, Cruccu G, Baron R, et al. EFNS guidelines on the pharmacological treatment of neuropathic pain: 2010 revision. Eur $J$ Neurol. 2010;17:1113-e88.

15. Haanpää ML, Backonja MM, Bennett MI, et al. Assessment of neuropathic pain in primary care. Am J Med. 2009;122(10Suppl.):S13-S21. 
16. Kalso E. The vicious circle in chronic pain management: balancing efficacy and adverse effects. Curr Med Res Opin. 2011;27:2069-2071.

17. Jorge LL, Feres CC, Teles VE. Topical preparations for pain relief: efficacy and patient adherence. J Pain Res. 2011;4:11-24.

18. Mick G, Correa-Illanes G. Topical pain management with the $5 \%$ lidocaine medicated plaster - a review. Curr Med Res Opin. 2012;28: 937-951.

19. World Health Organization. ICD-10 version 2010: Dorsalgia. Available from: http://apps.who.int/classifications/icd10/browse/2010/en\#/M54. Accessed July 02, 2014.

20. Galer BS, Gammaitoni AR. More than 7 years of consistent neuropathic pain relief in geriatric patients. Arch Intern Med. 2003;163:628.

21. Wilhelm IR, Tzabazis A, Likar R, Sittl R, Griessinger N. Long-term treatment of neuropathic pain with a $5 \%$ lidocaine medicated plaster. Eur J Anaesthesiol. 2010;27:169-173.

22. Sabatowski R, Hans G, Tacken I, Kapanadze S, Buchheister B, Baron R. Safety and efficacy outcomes of long-term treatment up to 4 years with $5 \%$ lidocaine medicated plaster in patients with post-herpetic neuralgia. Curr Med Res Opin. 2012;28:1337-1346.

23. Campbell BJ, Rowbotham M, Davies PS, Jacob P 3rd, Benowitz NL. Systemic absorption of topical lidocaine in normal volunteers, patients with post-herpetic neuralgia, and patients with acute herpes zoster. J Pharm Sci. 2002;91:1343-1350.

24. Müller-Schwefe GHH. European survey of chronic pain patients: results for Germany. Curr Med Res Opin. 2011;27:2099-2106.
25. Kozma CM, Provenzano DA, Slaton TL, Patel AA, Benson CJ. Complexity of pain management among patients with nociceptive or neuropathic neck, back, or osteoarthritis diagnoses. J Manag Care Pharm. 2014;20:455-466.

26. Freynhagen R, Baron R. The evaluation of neuropathic components in low back pain. Curr Pain Headache Rep. 2009;13:185-190.

27. Likar R, Kager I, Obmann M, Pipam W, Sittl R. Treatment of localized neuropathic pain after disk herniation with $5 \%$ lidocaine medicated plaster. Int J Gen Med. 2012;5:689-692.

28. Nicolaou A, Nicholson B, Hans G, Brasseur L. Outcome predictors for treatment success with $5 \%$ lidocaine medicated plaster in low back pain with neuropathic components and neuropathic pain after surgical and nonsurgical trauma. J Pain Res. 2011;4:25-38.

29. Parsons B, Schaefer C, Mann R, et al. Economic and humanistic burden of post-trauma and post-surgical neuropathic pain among adults in the United States. J Pain Res. 2013;6:459-469.

30. Hans G, Joukes E, Verhulst J, Vercauteren M. Management of neuropathic pain after surgical and non-surgical trauma with lidocaine 5\% patches: study of 40 consecutive cases. Curr Med Res Opin. 2009;25:2737-2743.

31. Correa-Illanes G, Calderón W, Roa R, Piñeros JL, Dote J, Medina D. Treatment of localized post-traumatic neuropathic pain in scars with 5\% lidocaine medicated plaster. Local Reg Anesth. 2010;3: $77-83$.
International Journal of General Medicine

\section{Publish your work in this journal}

The International Journal of General Medicine is an international, peer-reviewed open-access journal that focuses on general and internal medicine, pathogenesis, epidemiology, diagnosis, monitoring and treatment protocols. The journal is characterized by the rapid reporting of reviews, original research and clinical studies across all disease areas.

\section{Dovepress}

A key focus is the elucidation of disease processes and management protocols resulting in improved outcomes for the patient.The manuscript management system is completely online and includes a very quick and fair peer-review system. Visit http://www.dovepress.com/ testimonials.php to read real quotes from published authors. 